\title{
The effect of Leaders Strategic Improvisation and TQM on SME's Performance: Examining Mediating Role of Corporate Entrepreneurship
}

\section{Majid Ibrahim Mohammed Abdullah Al Zarooni, Prof. Dr Bashawir Bin Haji AbdulGanni}

1International Business Department, school of international Business, University of Utara

MalaysiaEmail:zarooni.majid@gmail.com2International

Business Department, school of international Business, University of Utara Malaysia

Article History: Received:11 January 2021; Accepted: 27 February 2021; Published online: 5 April 2021

\begin{abstract}
The main purpose of present study is to examine the effect of strategic improvisation and total quality management on performance. This study also examined the mediating effect of corporate entrepreneurship between strategic improvisation and total quality management on performance. The data was collected from the employees of SME's through questionnaires. For collection of data simple random sampling was adopted. The response rate of study was $60.04 \%$. the gathered data was assessed by using PLS-SEM through smart PLS-3.3.2. Its been revealed from the findings of the study that there exist positive relationship among strategic improvisation, TQM and SME Performance. Moreover, mediating role of corporate entrepreneurship is confirmed as well. The findings of present study are helpful for the policy makers of SME sector to develop strategy to improve organizational performance.
\end{abstract}

Keywords: Corporate Entrepreneurship, Leaders Strategic Improvisation, Total Quality Management, Small and Medium Enterprises, Performance

\section{INTRODUCTION}

Due to sheer global competition, quality is the key factor for maintaining competitive edge. In order to bolster customer satisfaction, an excellent quality service should be maintained. Poor quality product not only results in immediate rectification of sales but also causes a sharp decline in future projections of an organization. Innovations in information technology have resulted in informed customers by diffusing virtual geographical barriers (Hosseini, Soltani, \& Mehdizadeh, 2018).

As business environment has grown from local to global, the dynamics of marketplace have become increasingly complex. This has put organizational management under tremendous pressure to maintain competitive edge by constantly improving the logistic supply of the company along with cutting down the operational cost. Due to easy access to a wide range of services, every individual is becoming aware of the standards an organization must provide for a particular product. The implementation of Total Quality Management (TQM) has become essential for organizations due to an ever-increasing demand of quality of products in global market. TQM has shaped much of the product delivery standards seen in the modern marketplace (Singh \& Singh, 2014).

Similarly, improvisation according to the customer needs and demands has become essentially important in modern business environment. Improvisation help managers assess real time situations and improve products and services according to the needs. It has a potential to increase the organization's capital by merging the flexibility and innovation to standard practices. By implementing the practice of innovation, organizations can gain insight into how different individuals and groups adjust and cope according to the ever-changing customer demands and perform under time constraints while still maintaining flexibility (Ahmad, Arshad, \& Marchalina, 2015).

In order to survive, organizations must adapt to innovative ways to gain competitive edge over the other due to ever-changing economic, environmental and organizational environment. An organization will face eventual demise if it doesn't incorporate innovative practices in its policies. One of the ways to maintain an exponential growth curve is by tending to entrepreneurial environment i.e. appreciating entrepreneurial values in the organization. By implementing this policy, innovation has gained the importance of being subfield of entrepreneurship by accelerating performance and efficiency of a company (Kamatigam, 2017).

Academics have over time realized the importance of corporate entrepreneurship (CE) in improving company's performance (Hornsby, Kuratko, Shepherd, \& Bott, 2009). Identifying, weighing up and acting upon the selected entrepreneurial opportunity are the key components of CE. An entrepreneur has the responsibility to cultivate the very idea, to accept any associated risks and to maintain the company's inertia. Recently, academics and researchers have shown that the responsibility for implementing CE relies essentially on the shoulders of top management of any organization. Thus, enabling the top management by focusing on their roles and processes can result in CE activity in major organizations (Kamatigam, 2017). 
Studying performance parameters of small and medium enterprises (SMEs) has several advantages. First, GDP of a country is strongly influenced by SMEs and it has a major influence on the reduction of unemployment and poverty with the exception of centralized economies (which themselves are on the verge of extinction (Robu, 2013). Second, the importance of SMEs has significantly increased in recent years due to the rapid changing environment of world economics and the interdependency of different national economies due to its ability to rapidly adapt to rising challenges. Third, SMEs are considered to be vital entrepreneurial initiatives in context of competitive economical dynamics (Misoska, Dimitrova, \& Mrsik, 2016).

Most of the empirical studies on SMEs have focused on organizational level performance parameters i.e. understanding relationship of SMEs to their internal natural environment with a combination of some extrinsic factors (Cicea, Popa, Marinescu, \& Cătălina Ștefan, 2019). The aim of present study is to introduce corporate entrepreneurship as a mediating variable in the relationship between leaders' strategic improvisation, TQM and performance in the UAE. Hence, this study assesses corporate level entrepreneurship in terms of TQM and strategic innovations in UAE.

\subsection{LITERATURE REVIEW}

\section{SMEs' Performance}

SMEs are often defined according the country's or organization's own judgements such as the number of employees, the total value of a company and the revenue generated. Small and medium enterprises cover a wide range of fields such as agriculture, electronics, textile, services, products and others (Anggadwita \& Mustafid, 2014).

The success of organization is often defined in terms of firm performance. It explains the defined objectives achieved under the implementation of formulated strategic policies. Formally, performance of an organization can be defined as: the comparison of the expected value perceived by the owners to the actual value of a company. In other words, it is a construct under which any organization hopes to actualize its defined objectives. Thus, empirical value of performance can be calculated by comparing the actual output of an organization to its input. This in turn will help organization to emphasize neglected sectors by assessing performance parameters such as quality, innovation, cost and time. Thus, firm performance is the organization's ability to achieve its objectives by utilizing available resources in an efficient manner (Arshad \& Arshad, 2019).

According to Anggadwita and Mustafid (2014) the firm performance can be assessed by looking at the owner's satisfaction on a number of variables: the revenue generated, the profit, and business growth. Although, plethora of research has been conducted to define and assess performance parameters at organizational level, the same is scarce for small and medium enterprises.

\section{Corporate Entrepreneurship}

Corporate entrepreneurship consists of five major activity dimensions including innovation, autonomy, riskmanagement, competitiveness and pro-activeness. CE is often seen as amalgam of two types of problems namely 1) inter-organizational cooperation involving internal innovation 2) remodelling organizational form using modern renewal policies in order to create wealth. Previously, CE was defined as an innovation strategy to give a fresh feel to organization, industrialization to provide competitive edge or utilizing company's internal resources to boost up the firm performance.

Researchers have defined $\mathrm{CE}$ as process which is present in existing companies and regardless of the total size leads not only to the creation of new opportunities but also gives rise to new services, business and products leading to competitive advantage (Nur, Tjare, \& Dian, 2016).

\section{Total Quality Management}

Quality is considered to be a prime factor for success in this age of global competition. The role of quality management is to ensure an excellent quality product or a service that meets the customer's demands and inventing new ways that can satisfy their needs. A number of policies and tools can be implemented to ensure total quality management.

One of the key management strategies is the implementation of total quality management (TQM) to ensure good quality service or a product. It is defined as a construct that aims at continuous improvement in organization's processes and protocols in order to produce and deliver services and products in line with customer's satisfaction while it being cheaper, faster and easier in comparison to other similar products (Kaur, Singh, \& Ahuja, 2013). 
TQM's critical performance factors have been identified and evaluated by numerous studies according to its natural environment and intrinsic factors. Studies identified different factors including teamwork, external management, logistics, information management, communication, quality improvement, supply chain management and orientation to customer\# satisfaction (Al-Dhaafri, Al-Swidi, \& van der Wiele, 2016).

\section{Leaders' Strategic Improvisation}

Strategic innovation and improvisation are one of the new constructs that allow organizations to maintain competitive relevance especially in today's turbulent economic environment by allowing flexibility and adaptability. Strategic innovation (SI) is defined as an ability to streamline knowledge, process and resources in real time to create an innovative problem-solving pathway which is still grounded in current realities. Under the context of current study, it is defined as a leader's ability to perceive unforeseen situations and improvise efficiently or effectively to solve a problem. In essence, SI is implementation of planning and processes resulting the emergent behavior of an organization (Bakar, Mahmood, \& Ismail, 2015).

SI is implemented in real time scenarios and situations which involve a great degree of innovation and spontaneity. SI is able to manifest itself only when leader is able to respond to unforeseen circumstances intelligently to solve a problem. Thus, a creative decision must be made outside of formal organizational structure under real time situations. It is more of a behavioral strategy that is used by organization's leaders to respond to difficult situations in time and as efficiently as possible (Ahmad Arshad, Razalli, Abu Bakar, Ahmad, \& Mahmood, 2015).

SI is being viewed as excellent construct to implement strategic adaptation, learning and renewal. Under everchanging dynamics of economy, organizations often find themselves in tough situations to plan their way out. Eventually, employees are expected to act upon information before it is properly scrutinized, and all options analysed. Resultantly, leaders will have to improvise and adapt according to the complexity of situation. This will not only eradicate the existing crisis but will also help organization to capitalize the available opportunity (Ibrahim, Mahmood, \& Bakar, 2018).

\section{Relationship Building}

\section{Corporate Entrepreneurship and SMEs’ Performance}

Management should encourage the development of corporate entrepreneurship as well as its effect on innovation and performance. Studies have mentioned the possibility that factors which contribute in stimulating entrepreneurship at one organizational level might also hinder the entrepreneurial processes and activities at different levels in the same organization. It is suggested that different performance dimensions can possibly be influenced by different entrepreneurial postures at differing points in time; therefore, this relationship requires further scientific investigation (Karacaoglu, Bayrakdaroglu, \& San, 2013).

It is assumed that entrepreneurship which affects performance is likely to be different from one organization to another. Rather than driving performance independently, it is continuously interacting with other organizational factors. It is argued that firm performance is a multifaceted construct, which should be based on non-financial and financial measures. There has been a great debate in market orientation and entrepreneurship orientation as these variables not only help organizations in enhancing their capacity for managing the environment, but also in performing well. The degree to which market orientation and entrepreneurship affect organizational performance has long been a subject of interest (Zahra, 2015).

Past research also provides evidence that firm performance is not only influenced by entrepreneurial characteristics, but also contextual factors, organizational factors and strategies of the firm. entrepreneurial behaviour in terms of the pursuit of opportunities by innovatively using resource combinations is seen as very critical for the organization's survival, renewal, and profitable growth.

Past literature also states that the performance results of entrepreneurial activities could be measured as economic profit, product innovation, new venture growth, concern for public welfare and social legitimacy, or simply personal satisfaction. It is argued that the effectiveness of entrepreneurship is a function of organizational- and individual-level behaviour. Entrepreneur's individual level behaviour could influence organizational actions and the two are typically used may synonymously. Firms hope that entrepreneurial pastures would help them in creating and sustaining a high level of performance (He, Wang, \& Martínez-Fuentes, 2020).

Based on the literature, this study draws the following hypothesis:

H1: Corporate entrepreneurship has a significant impact on the SMEs' performance. 


\section{Total Quality Management and Corporate Entrepreneurship}

TQM enables organizations to long-term success to be able to respond effectively towards the demands of customers regrading service product/innovation, quality, price and speed. It also enables organizations to deal with continuously increasing and difficult customer demands to make improvements steadily and gain magnificent achievements, while adopting total quality management practices and quickly expand the industries. by adopting TQM practices, organizations ensure to practice their entrepreneurial activities by making innovative changes in organizations and gain ultimate competitive advantage.

Total quality management is all time changing phenomenon that includes innovation line while managing the organizations; it involves all-inclusive system, a variety in product modelling that enhances the overall performance of organizations (Ali \& Sawaean, 2019). The variation might be anything very new, or the alteration might be in existing product/services. Jalilvand, Pool, Jamkhaneh, and Tabaeeian (2018) has determined the indirect effect of TQM on Entrepreneurial orientations. Hence, the study postulates that:

\section{H2: Total Quality Management is positively related to corporate entrepreneurship.}

H3: Corporate Entrepreneurship mediates the relationship between TQM and SMEP.

\section{Leaders' Strategic Improvisation and Corporate Entrepreneurship}

Hmieleski and Corbett (2008) in their study on how improvisation affects innovative team performance. Their findings also confirmed a positive relationship between improvisation and team innovation, especially when moderated by team and contextual factors. However, the study also stated that improvisation may not be considered as right or wrong as it depends on the way and manner in which it is used. In another study using a sample of three young firms, Studies have examined the role of bricolage, improvisation, and action-giving towards the process of creating a new venture. The findings clearly explained that improvisation is part and parcel of the entrepreneurial process, which can produce both good and bad results.

The studies have established that strategic improvisation has direct link with corporate entrepreneurship as strategic product/service renewal and innovation is involved in it. It is empirically proven that innovation and entrepreneurial activities in organization have impact on the improvisation of managers and leaders (Vera \& Crossan, 2005). As well, Hmieleski and Corbett (2006) have linked strategic improvisation to new business or any venture and these all are the part of corporate entrepreneurship (Ibrahim et al., 2018).

Hence, it is hypothesized that:

H4: LSI is positively associated to corporate entrepreneurship.

H5: Corporate Entrepreneurship mediates the relationship between LSI and SMEP.

\section{Framework}

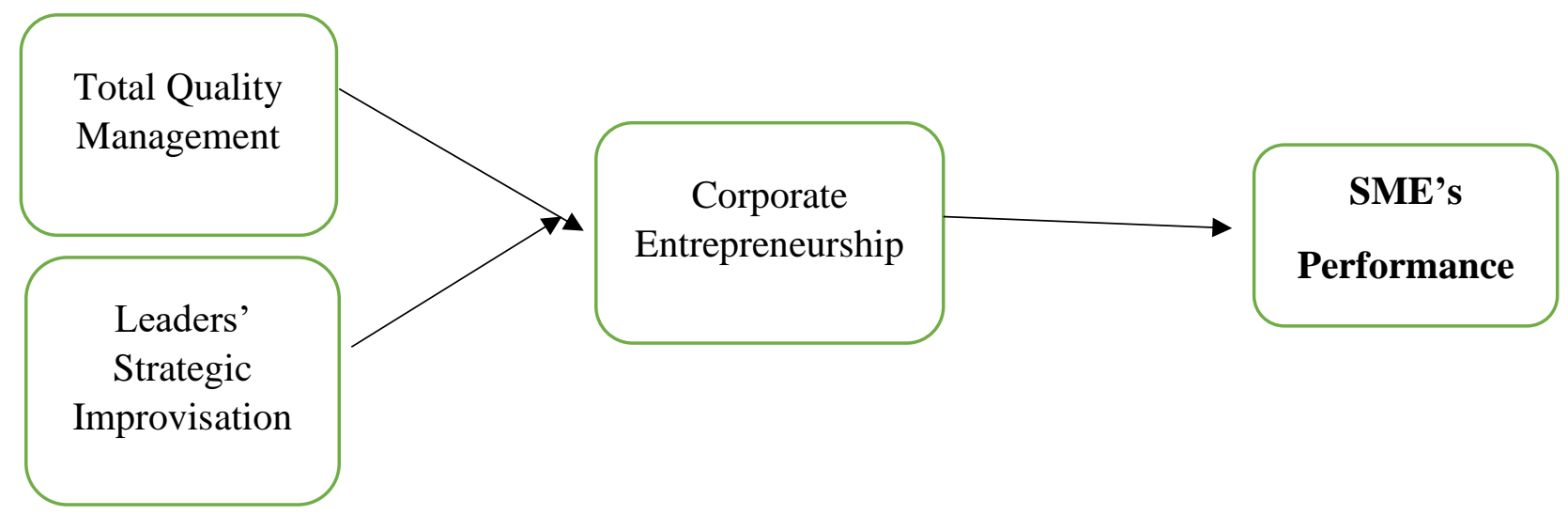

\subsection{RESEARCH METHODOLOGY}

The present study employs a deductive research approach as this emphasizes on theory testing and verification as opposed to developing a new theory. As well as, the current study adopts the positivist paradigm based on objectivism as the underlying ontological and epistemological positions. 
The present study adopts the quantitative research approach for assessing the structural relationship among the proposed latent variables. Using the Partial Least Square path modelling under Smart PLS 3, all the hypotheses were tested.

This study uses the cross-sectional research design under which the data for the whole study is collected all at once. the present study adopts the quantitative survey method. Since the target population of the present study consists of middle managers from UAE SMEs, these managers could best describe the organizational phenomenon in terms of their perception of the culture and performance of their respective SMEs. Hence, this study uses organization as the analysis unit as it allows both middle and senior managerial levels to be involved in the survey. The target populations are registered SMEs that are involved in foreign operations such as franchising or exporting.

The sample size of this study as determined by G*Power 3.1 software is 354 . This sample size was adjusted according to Salkind 's view and increased by 50\% which was 526 SMEs. The questionnaires were distributed to the randomly sampled SME's owner/managers and all the items in the questionnaire were answered using a sevenpoint Likert scale.

\subsection{ANALYSIS}

A total of 526 sets of questionnaires were distributed to the respondents of present study. The preliminary examination of the collected data was done using SPSS. Further analysis of data was done through PLS-SEM. Total response rate of study was $60.04 \%$. Male participants dominated the response rate $(64.7 \%)$ as compared to $35.23 \%$ female counterparts.

The PLS-SEM Path Model was utilized to test the hypothesized relationship between the endogenous and exogenous latent construct which can be visualized through the path diagrams (Joe F Hair, Ringle, \& Sarstedt, 2011). Analysing data using PLS-SEM is carried out based on two basic steps namely, the measurement model and structural model. Thus, in order to assess the reflective measurement model in this study, PLS-SEM algorithm was performed.

According to Hair Jr, Sarstedt, Hopkins, and Kuppelwieser (2014) outer loadings are considered reliable if it has indicators or items with outer loadings of at least between 0.40 . However, they recommended that indicators with less than the threshold should be removed from the model based on the presumption that it will increase the average variance extracted AVE and composite reliability. Therefore, the result revealed that all the indicators maintained on the reflective latent constructs have satisfied the minimum threshold of above 0.40 as suggested. Table 1 show the results of factor loading of data and Figure 2 below show the results of measurement model.

Table 1: Factor Loading

\begin{tabular}{|l|l|l|l|l|}
\hline & CE & LSI & SMEP & TQM \\
\hline CE1 & 0.783 & & & \\
\hline CE11 & 0.657 & & & \\
\hline CE12 & 0.637 & & & \\
\hline CE13 & 0.650 & & & \\
\hline CE2 & 0.811 & & & \\
\hline CE3 & 0.742 & & & \\
\hline CE4 & 0.813 & & & \\
\hline CE5 & 0.661 & & & \\
\hline CE6 & 0.748 & & & \\
\hline CE7 & 0.652 & & & \\
\hline CE8 & 0.677 & & & \\
\hline CE9 & 0.628 & & & \\
\hline LSI1 & & 0.686 & & \\
\hline LSI2 & & 0.719 & & \\
\hline LSI3 & & 0.746 & & \\
\hline LSI4 & & 0.742 & & \\
\hline
\end{tabular}


The effect of Leaders Strategic Improvisation and TQM on SME's Performance: Examining Mediating Role of Corporate Entrepreneurship

\begin{tabular}{|l|l|l|l|l|}
\hline LSI5 & & 0.727 & & \\
\hline LSI7 & & 0.665 & & \\
\hline SMEP1 & & & 0.847 & \\
\hline SMEP2 & & & 0.831 & \\
\hline SMEP3 & & & 0.852 & \\
\hline SMEP4 & & & 0.807 & \\
\hline SMEP5 & & & 0.597 & \\
\hline SMEP6 & & & 0.812 & \\
\hline SMEP7 & & & 0.818 & \\
\hline SMEP8 & & & 0.854 & 0.781 \\
\hline TQM1 & & & & 0.846 \\
\hline TQM2 & & & & 0.828 \\
\hline TQM3 & & & & 0.852 \\
\hline TQM4 & & & & 0.845 \\
\hline TQM5 & & & \\
\hline TQM7 & & & \\
\hline
\end{tabular}

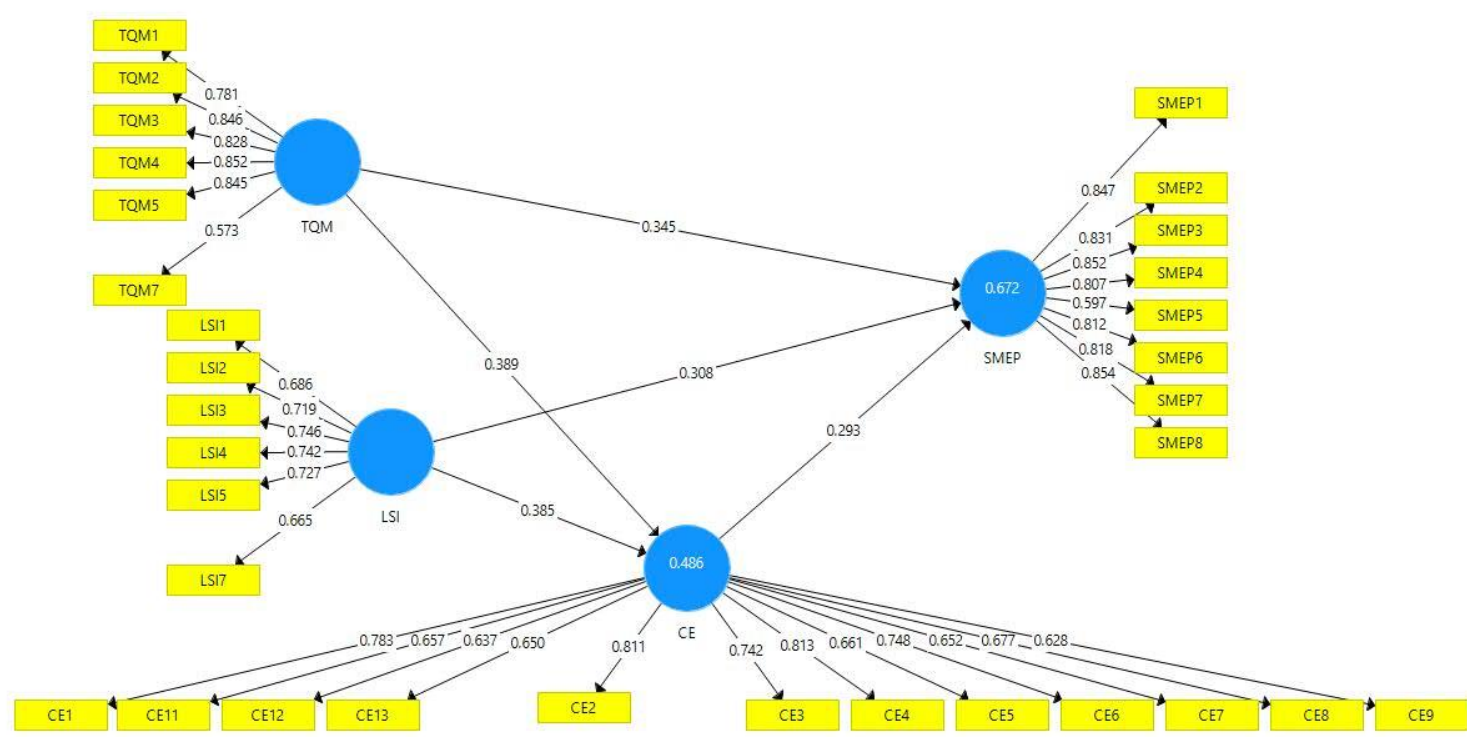

Figure 2 Measurement Model

Note $=$ TQM- total quality management, LSI=Leader's Strategic Improvisation, SMEP= SMEs Performance, $C E=$ corporate information, $O C=$ organizational culture

According to Hair et al., (2017), the values of the items are retained if the AVE value is more than 0.50. The table 2 shows all values are more than 0.50 .

Table 2: Reliability and Validity

\begin{tabular}{|l|l|l|l|l|}
\hline & \multicolumn{1}{|c|}{ Cronbach's Alpha } & \multicolumn{1}{|c|}{ rho_A } & \multicolumn{1}{c|}{$\begin{array}{c}\text { Composite } \\
\text { Reliability }\end{array}$} & $\begin{array}{c}\text { Average Variance } \\
\text { Extracted (AVE) }\end{array}$ \\
\hline CE & 0.909 & 0.913 & 0.923 & 0.501 \\
\hline LSI & 0.810 & 0.814 & 0.862 & 0.511 \\
\hline
\end{tabular}




\begin{tabular}{|l|l|l|l|l|}
\hline SMEP & 0.921 & 0.930 & 0.936 & 0.650 \\
\hline TQM & 0.878 & 0.887 & 0.910 & 0.630 \\
\hline
\end{tabular}

Discriminant validity represents the extent to which a latent variable stands distinct from other latent constructs in the model. Specifically, discriminant validity is an indication that a construct stands unique and has explained a unique phenomenon that has not been significantly explained by other latent constructs in the model based on empirical standard (Hair Jr et al., 2014). However, it is determined through two basic approaches; the first is by applying the Fornell and Larcker (1981) criterion. Second, is by making comparison between indicator loadings of one latent construct and that of the other latent constructs in the model as suggested by Chin (1998).

The discriminant validity in this study was achieved by using Fornell and Larcker (1981) and Chin (1998). According to the criterion discriminant validity can be determined by making comparison among the latent constructs thereby calculating the square root of average variance extracted AVE. The criteria as suggested by Fornell and Larcker (1981) stipulates that square root of average variance extracted AVE should be greater than its correlations with other latent constructs in the model.

Table 3: Discriminant Validity Fornell and Larcker (1981)

\begin{tabular}{|l|l|l|l|l|}
\hline & CE & LSI & SMEP & TQM \\
\hline CE & 0.708 & & & \\
\hline LSI & 0.627 & 0.715 & & \\
\hline SMEP & 0.703 & 0.707 & 0.806 & \\
\hline TQM & 0.629 & 0.623 & 0.721 & 0.794 \\
\hline
\end{tabular}

The next step after confirmation of measurement model of this research, next structural model was evaluated for confirming the hypothesized relationship of the study. For this purpose, bootstrapping procedure was used through 5000 subsamples.

After confirming measurement model, researcher in this study proceeded towards the structural model to test the hypotheses. Based on the study model, all the direct effect hypotheses were tested according to the postulations. Specifically, the variables involved are TQM, LSI, CE, and SMEP. The endogenous latent construct in the model is SMEP. Following table show the results of direct relationships:

Table 4: Direct Result

\begin{tabular}{|l|l|l|l|l|l|}
\hline & $\begin{array}{l}\text { Original Sample } \\
(\mathbf{O})\end{array}$ & $\begin{array}{l}\text { Standard Deviation } \\
(\text { STDEV })\end{array}$ & $\begin{array}{l}\text { T Statistics } \\
(\mid \text { O/STDEV })\end{array}$ & P Values \\
\hline CE -> SMEP & 0.293 & 0.046 & 6.364 & $\mathbf{0 . 0 0 0}$ \\
\hline LSI -> CE & 0.385 & 0.046 & 8.456 & $\mathbf{0 . 0 0 0}$ \\
\hline LSI -> SMEP & 0.308 & 0.051 & 6.004 & $\mathbf{0 . 0 0 0}$ \\
\hline TQM -> CE & 0.389 & 0.048 & 8.098 & $\mathbf{0 . 0 0 0}$ \\
\hline TQM -> SMEP & 0.345 & 0.053 & 6.568 & $\mathbf{0 . 0 0 0}$ \\
\hline
\end{tabular}

Based on the results presented in the above Table, it indicates that CE has significant direct effect on SMEP with $(\beta=0.293, t=6.364)$ implying that the result is statistically significant. LSI has significant direct effect on CE with $(\beta=0.385, \mathrm{t}=8.456)$ implying that the result is statistically significant. LSI has significant direct effect on SMEP with $(\beta=0.308, \mathrm{t}=6.004)$ implying that the result is statistically significant. TQM has significant direct effect on CE with $(\beta=0.389, \mathrm{t}=8.098)$ implying that the result is statistically significant. TQM has significant direct effect on SMEP with $(\beta=0.345, \mathrm{t}=6.568)$ implying that the result is statistically significant.

The mediation analysis will focus on establishing a path where the exogenous construct will transmit effect to the endogenous latent construct indirectly through the mediating mechanism (Ramayah, Yeap, Ahmad, Halim, \& Rahman, 2017). Following table show the results of direct relationships:

Table 5: Mediation Results

\begin{tabular}{|l|ll|l|l|l|}
\hline & $\begin{array}{l}\text { Original } \\
(\text { O) }\end{array}$ & Sample & $\begin{array}{l}\text { Standard } \\
\text { Deviation } \\
\text { (STDEV })\end{array}$ & $\begin{array}{l}\text { T Statistics } \\
(\mid \text { O/STDEV })\end{array}$ & P Values \\
\hline
\end{tabular}


The effect of Leaders Strategic Improvisation and TQM on SME's Performance: Examining Mediating Role of Corporate Entrepreneurship

\begin{tabular}{|l|l|l|l|l|}
\hline LSI $->$ CE $->$ SMEP & 0.113 & 0.022 & 5.067 & $\mathbf{0 . 0 0 0}$ \\
\hline TQM $>$ C CE $>$ SMEP & 0.114 & 0.021 & 5.436 & $\mathbf{0 . 0 0 0}$ \\
\hline
\end{tabular}

Nevertheless, the result of the analysis on mediating role of CE on the effect of TQM on SMEP has the coefficient of $(\beta=0.114, t=5.436, \mathrm{p}<0.000)$ and the mediating role of CE on the effect of LSI on performance has the coefficient of $(\beta=0.113, t=5.067, \mathrm{p}<0.000)$. Based on the result the entire two hypothesis were supported.

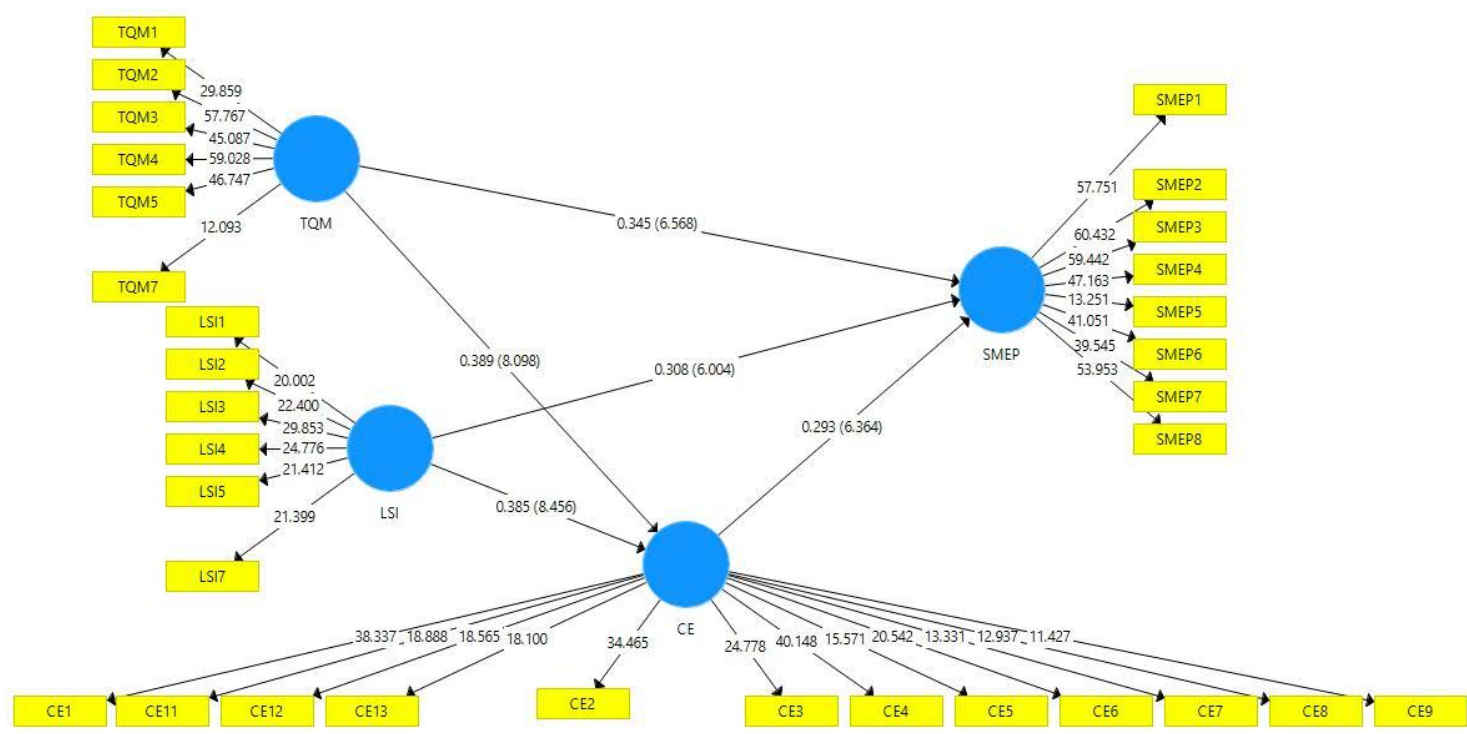

Figure 3. Structural Model

Note $=$ TQM- total quality management, LSI=Leader's Strategic Improvisation, SMEP $=$ SMEs Performance, $C E=$ corporate information, $O C=$ organizational culture

The R-squared value stands for figure that explain the proportion of variance in the endogenous latent construct which has been significantly explained by the exogenous constructs. many scholars have prescribed a threshold for acceptable R-squared value. Even though, the acceptability of a given R-squared value depends on the context within which the research study is undertaken (Joseph F Hair, 2010). Following Table show the values of Rsquare

\section{Table 6: R Square}

\begin{tabular}{|l|l|}
\hline & R Square \\
\hline CE & 0.486 \\
\hline SMEP & 0.672 \\
\hline
\end{tabular}

\subsection{DISCUSSION AND CONCLUSION}

The results of present study show that performance of SME's improves because managers tried new approaches to solve the problems. Additionally, they believe that they were able to identify opportunities for new ideas and processes; thus, risks were taken for producing new ideas which contributed positively on performance of SME's. This is because respondents think that e-commerce processing positively affects improvisational skills, which in turn enhances internal processing performance, customer satisfaction, learning and growth as well as financial performance of SME's. Thus, organizations who invest in building strategies of leaders' improvisation, get improved organizational performance results in SME's.

The results of current research show that performance of SME's improves because managers thinks that their firms implements programs to improve the quality and reliable delivery of materials and components provided by suppliers; along with reduction of non-value added and time delays activities in the production process. coordination of quality improvement between parts of the organization ultimately strengthens the total quality 
principles of organizations. Thus, organizations who invest in total quality provision principles, get improved performance results in SME's.

The study resulted that the firm's learning, creation (creativity), or achievement by implementing a corporate entrepreneurial strategy influences firm performance. Hence, implementation of corporate entrepreneurial (CE) strategies in SME's is a solution to establish firms on strong grounds; achieve high performance and gain sustainable competitive advantage in current dynamic corporate environment. $\mathrm{CE}$ is considered as the strategic mediator between TQM \& SMEP and LSI \& SMEP. Hence, if SME's desire to improve their long-term performance and growth, they should focus of their leader's improvisation, their product quality and entrepreneurial skills of their employees.

\section{REFERENCES}

1. Ahmad Arshad, D., Razalli, M. R., Abu Bakar, L. J., Ahmad, H., \& Mahmood, R. (2015). Exploring the incidence of strategic improvisation: Evidence from Malaysian government link corporations. Asian Social Science, 11(24), 105-112.

2. Ahmad, H., Arshad, D., \& Marchalina, L. (2015). Entrepreneurial orientation, strategic improvisation, talent management and firm performance. Journal of Business Economics and Finance, 4(1).

3. Al-Dhaafri, H. S., Al-Swidi, A., \& van der Wiele, T. (2016). The impact of total quality management and entrepreneurial orientation on organizational performance. International Journal of Quality \& Reliability Management.

4. Ali, K. A. M., \& Sawaean, F. (2019). The Impact of Entrepreneurial Leadership, TQM Practices, and Innovation Management on Organizational Performance of SMEs in Kuwait.

5. Anggadwita, G., \& Mustafid, Q. Y. (2014). Identification of factors influencing the performance of small medium enterprises (SMEs). Procedia-Social and Behavioral Sciences, 115, 415-423.

6. Arshad, M., \& Arshad, D. (2019). Internal capabilities and SMEs performance: A case of textile industry in Pakistan. Management Science Letters, 9(4), 621-628.

7. Bakar, H. A., Mahmood, R., \& Ismail, N. N. H. N. (2015). Fostering small and medium enterprises through entrepreneurial orientation and strategic improvisation. Mediterranean Journal of Social Sciences, 6(4), 481-481.

8. Chin, W. W. (1998). The partial least squares approach to structural equation modeling. Modern methods for business research, 295(2), 295-336.

9. Cicea, C., Popa, I., Marinescu, C., \& Cătălina Ștefan, S. (2019). Determinants of SMEs' performance: evidence from European countries. Economic research-Ekonomska istraživanja, 32(1), 1602-1620.

10. Fornell, C., \& Larcker, D. F. (1981). Evaluating structural equation models with unobservable variables and measurement error. Journal of marketing research, 18(1), 39-50.

11. Hair, J. F. (2010). Black, Wc, Babin, Bj, \& Anderson, Re (2010). Multivariate data analysis, 7.

12. Hair, J. F., Ringle, C. M., \& Sarstedt, M. (2011). PLS-SEM: Indeed a silver bullet. Journal of Marketing theory and Practice, 19(2), 139-152.

13. Hair Jr, J. F., Sarstedt, M., Hopkins, L., \& Kuppelwieser, V. G. (2014). Partial least squares structural equation modeling (PLS-SEM): An emerging tool in business research. European business review.

14. He, Q., Wang, M., \& Martínez-Fuentes, C. (2020). Impact of corporate entrepreneurial strategy on firm performance in China. International Entrepreneurship and Management Journal, 16, 1427-1444.

15. Hmieleski, K. M., \& Corbett, A. C. (2006). Proclivity for improvisation as a predictor of entrepreneurial intentions. Journal of Small Business Management, 44(1), 45-63.

16. Hmieleski, K. M., \& Corbett, A. C. (2008). The contrasting interaction effects of improvisational behavior with entrepreneurial self-efficacy on new venture performance and entrepreneur work satisfaction. Journal of business venturing, 23(4), 482-496.

17. Hornsby, J. S., Kuratko, D. F., Shepherd, D. A., \& Bott, J. P. (2009). Managers' corporate entrepreneurial actions: Examining perception and position. Journal of business venturing, 24(3), 236-247.

18. Hosseini, A. S., Soltani, S., \& Mehdizadeh, M. (2018). Competitive advantage and its impact on new product development strategy (Case study: Toos Nirro technical firm). Journal of Open Innovation: Technology, Market, and Complexity, 4(2), 17.

19. Ibrahim, N. A., Mahmood, R., \& Bakar, M. S. (2018). Strategic improvisation and HEIs performance: the moderating role of organizational culture. PSU Research Review.

20. Jalilvand, M. R., Pool, J. K., Jamkhaneh, H. B., \& Tabaeeian, R. A. (2018). Total quality management, corporate social responsibility and entrepreneurial orientation in the hotel industry. Social Responsibility Journal. 
21. Kamatigam, C. (2017). Corporate Entrepreneurship: Exploring the role of leaders; supervision by means of employee creativity and innovation.

22. Karacaoglu, K., Bayrakdaroglu, A., \& San, F. B. (2013). The impact of corporate entrepreneurship on firms' financial performance: Evidence from Istanbul Stock Exchange Firms. International Business Research, 6(1), 163.

23. Kaur, M., Singh, K., \& Ahuja, I. S. (2013). An evaluation of the synergic implementation of TQM and TPM paradigms on business performance. International Journal of Productivity and Performance Management.

24. Misoska, A. T., Dimitrova, M., \& Mrsik, J. (2016). Drivers of entrepreneurial intentions among business students in Macedonia. Economic research-Ekonomska istraživanja, 29(1), 1062-1074.

25. Nur, A. L. N., Tjare, A. T., \& Dian, P. (2016). The Effect of Corporate Entrepreneurship on Firm Performance (Case Study on SMEs Processing Refined Seaweed Product in South Sulawesi, Indonesia). European Journal of Business and Management, 8(3), 108-114.

26. Ramayah, T., Yeap, J. A., Ahmad, N. H., Halim, H. A., \& Rahman, S. A. (2017). Testing a confirmatory model of Facebook usage in SmartPLS using consistent PLS. International Journal of Business and Innovation, 3(2), 1-14.

27. Robu, M. (2013). The dynamic and importance of SMEs in economy. The USV annals of economics and public administration, 13(1 (17)), 84-89.

28. Singh, H., \& Singh, B. (2014). Total quality management: today's business excellence strategy. International Letters of Social and Humanistic Sciences, 21, 188-196.

29. Vera, D., \& Crossan, M. (2005). Improvisation and innovative performance in teams. Organization science, 16(3), 203-224.

30. Zahra, S. A. (2015). Corporate entrepreneurship as knowledge creation and conversion: The role of entrepreneurial hubs. Small Business Economics, 44(4), 727-735. 